\title{
Perceived Efficacy and Attitude of Undergraduate Medical Students towards Teaching Learning Media
}

\author{
H. Sagili ${ }^{1}$, N. Chourasia ${ }^{2}$, L. Subitha ${ }^{3}$, P. Dasari ${ }^{4}$
}

\begin{abstract}
Purpose: Obtaining knowledge of learners and their preferences is vastly underutilized in classroom instruction. This study aimed to assess attitudes of medical undergraduate towards PowerPoint, overhead projector and chalkboard teaching and to compare the perceived efficacy of the three teaching aids.
\end{abstract}

Methodology: This cross sectional descriptive study was carried out in a medical college in Puducherry during January - February 2012. A self-administered questionnaire in English was given to all undergraduate medical students. The perceived efficacy of the different teaching methods was assessed using a 5 point Likert scale, while preferences and views were collected using open ended questions.

Results: Response rate was 98.3\% (361/367). Combination of PowerPoint and blackboard was preferred by $85 \%$. PowerPoint method was preferred for information content, visual enhancement, organised nature and overall delivery of the topics. Blackboard was perceived to be better for making lectures understandable, providing better grasp and retention, resulting in better impact. Transparencies were considered 'out dated, unclear, unattractive, boring and not useful' by the majority, and illustrations and graphics were preferred for better retention.

Conclusions: Though PowerPoint was found suitable for the visual content and presentation style, students preferred a combination of PowerPoint and blackboard for lecture delivery, while use of transparencies was not preferred. These findings suggest need for changes in the current practice to facilitate overall improvement of the teaching learning experience.

Key words: Power Point, Overhead Projector, Chalkboard Teaching

\section{Introduction}

Teaching learning media are the means of communicating educational information. Lectures have been the most common form of teaching and learning (Brown \& Atkins 1988). Chalkboard, overhead projector and PowerPoint teaching are commonly used teaching learning media in lectures, while the

\footnotetext{
${ }^{1}$ Associate Professor, Department of Obstetrics and Gynaecology

${ }^{2}$ Intern

${ }^{3}$ Assistant Professor,

${ }^{4}$ Professor, Department of Obstetrics and Gynaecology
}

Jawaharlal Institute of Postgraduate Medical Education \& Research (JIPMER), Pondicherry.605005, India

Corresponding Author:

MRS. Haritha Sagili, MD, MRCOG, MFSRH

Associate Professor, Department of Obstetrics and Gynaecology, JIPMER, Pondicherry. 605005. India

Email:harithasagili@gmail.com use of transparencies with an overhead projector (TOHP) has been also popular (Seth et al. 2010a). Recently the use of electronic presentations has become common and Microsoft PowerPoint (PPT) is now the most popular package used out of all electronic presentations (Prasad et al. 2000).

Few studies have been conducted to assess the effectiveness of lectures using PPT or other such media in comparison to lectures using chalkboard, or the use of TOHP with varying results. This study aimed to assess the attitude of undergraduate medical students towards PPT, overhead projector and chalkboard teaching and to compare the perceived efficacy of each of the three teaching aids used during lectures.

\section{Methods}

This cross sectional descriptive study was carried out at the Jawaharlal Institute of Postgraduate Medical Education \& 
Research (JIPMER), Puducherry, India. A selfadministered questionnaire in English was given to consenting medical undergraduates. Perceived efficacy of three different teaching methods namely PPT, overhead projector and chalkboard teaching was assessed using a 5point Likert scale, i.e., 5 (agree strongly), 4 (agree), 3 (no opinion), 2 (disagree) and 1 (disagree strongly). For each of the three methods, the students were asked to rank the following parameters on a five-point scale:

1. Contents were informative

2. Clear and understandable

3. Well organised

4. Helped grasp concepts better

5. Aroused interest in the topic

6. Visually enhanced \& better perceived

7. Increased impact of the lecture delivered

8. Helped retain concepts longer

9. Improved overall delivery of the topic

10. Helped maintain concentration throughout lecture
11. Better for self-study later on

12. Overloaded with information

Preferences and views on the use of these tools were collected using open ended questions.

\section{Results}

Age of the responders ranged from 18-25 years; $50.4 \%$ were males. An average of 2 to 3 lectures per day was attended by the majority (82\%). Students were equally distributed amongst the different years of study.

Combination of PowerPoint and blackboard was the preferred method of teaching by $85 \%$, while PowerPoint alone was preferred by $9 \%$. Blackboard alone was preferred by $3.9 \%$ and a combination of all three media was preferred by $2.8 \%$ of responders.(Figure 1 )

Figure 1: Preferred teaching learning aid

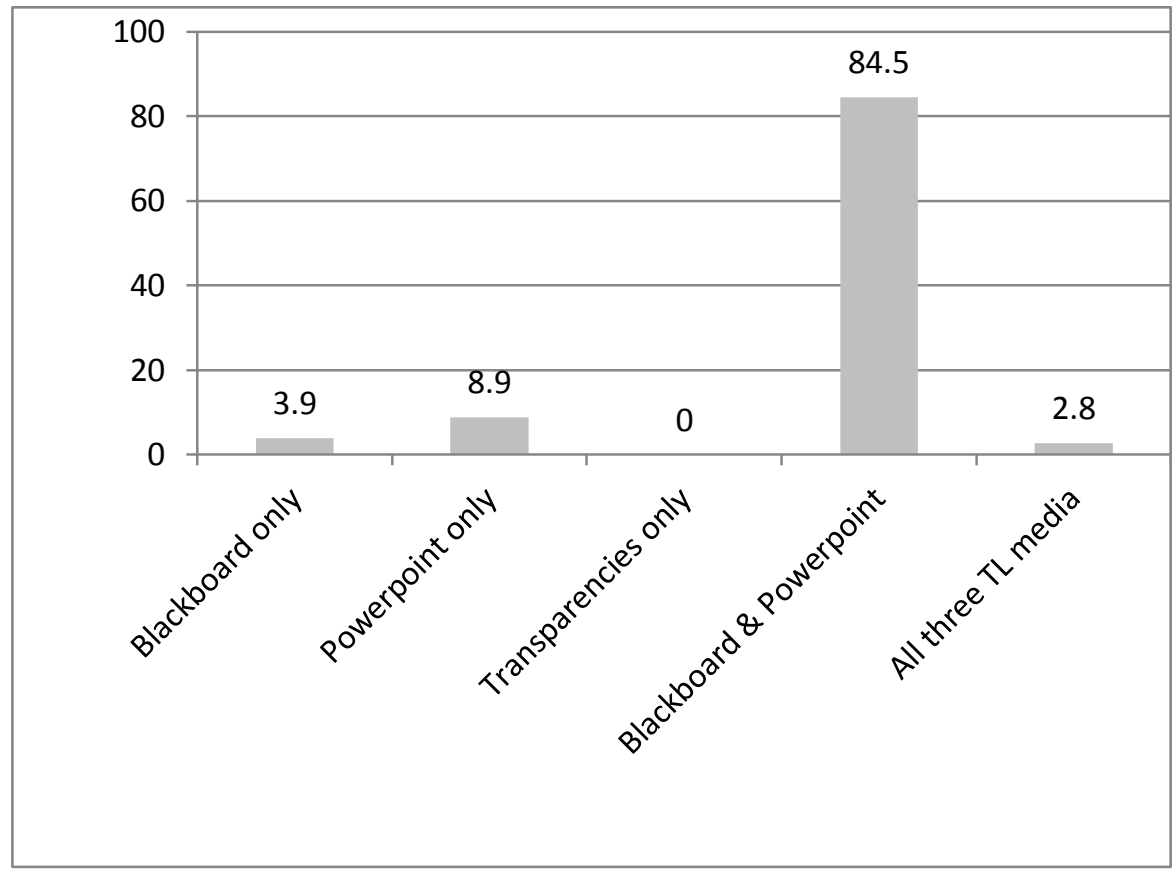

PowerPoint was perceived to be superior for the information content, visual enhancement, organised nature and overall delivery of the topics. Blackboard was perceived as a better tool for making the lectures understandable, for a better grasp and retention, resulting in better impact. Both these tools were rated as interesting by similar proportion of the respondents (Figure 2).
Transparencies were considered 'out dated, unclear, unattractive, boring and not useful' by majority of the students, and illustrations and graphics are preferred for better retention. Less than $2 \%$ of students suggested that 'transparencies may be used to summarise important points or to break the monotony of power points in all sessions'. 
Figure 2: Perceived efficacy and views on different teaching learning aids

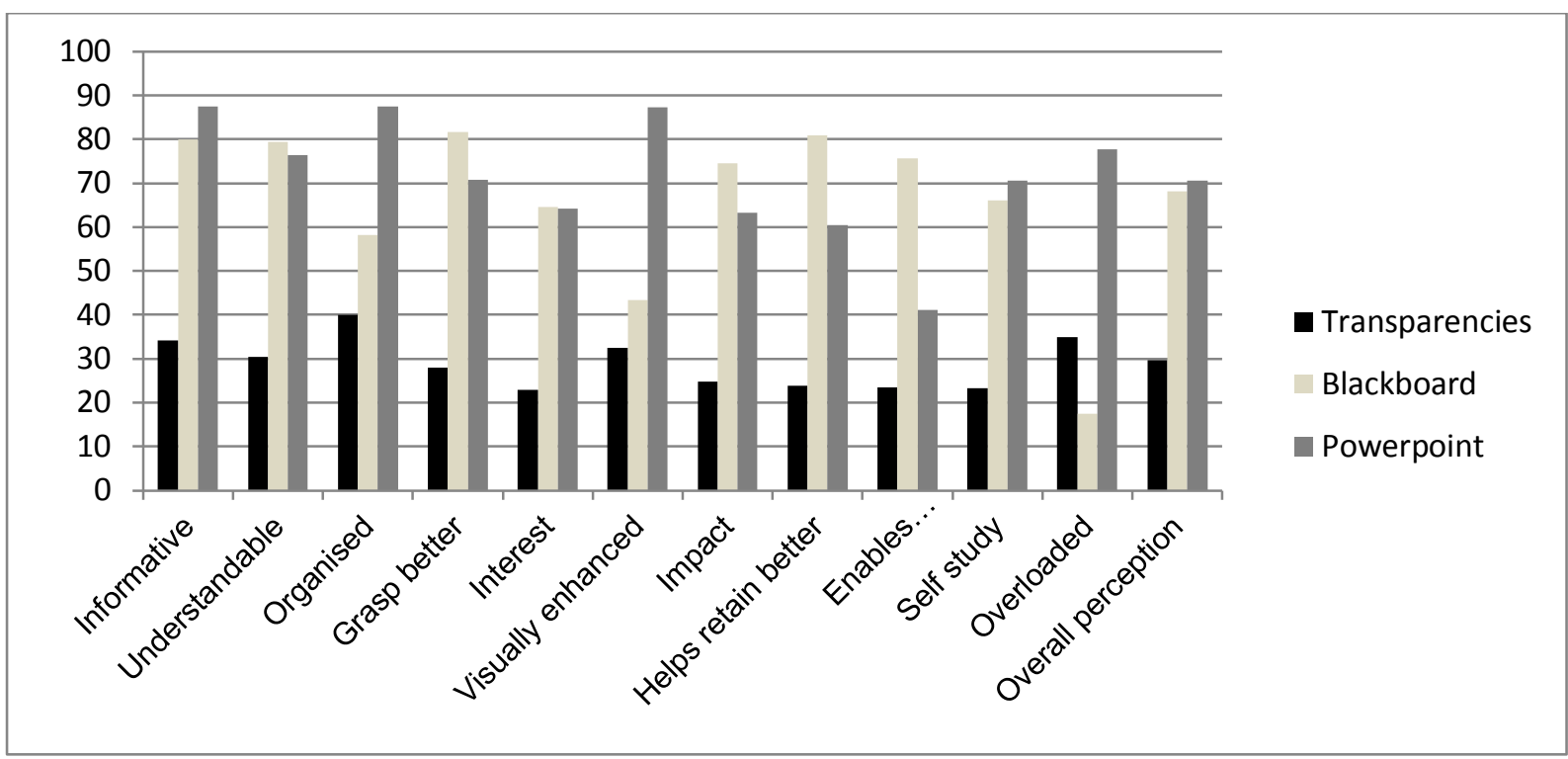

\section{Discussion}

Over the last two decades teachers seem to increasingly prefer the use of Power Point when compared to other methods to deliver lectures. But what do the students really want? This study has shown that majority (85\%) of the students in our setting preferred a combination of PowerPoint and chalkboard followed by PowerPoint/chalkboard used in isolation. They felt that the theoretical aspect of a topic could be discussed on chalkboard and pictures/videos relating to the lecture could be shown on PowerPoint. According to one study, traditional classes with blackboard presentation were the most favoured by students from biomedicine and medicine courses (Novelli \& Fernandes 2007), while another study observed that most students preferred PPT over traditional presentations (eg, chalk and talk) (Savoy et al., 2009).

Our students perceived blackboard as a better tool for making the lectures understandable, interesting, enabling better grasp and retention, resulting in better impact. $A$ chalkboard is uniquely effective as a medium of classroom instruction and has been used commonly in lectures, (Seth et al., 2010a). In the present study, students perceived PowerPoint as superior for information content, visual enhancement, interesting flow, organised nature and overall delivery of the topics. Similarly, Seth and colleagues (2010b) report that a majority of medical students preferred PPT because of better quality of texts and diagrams, graphs, animations and videos. It was considered ideal for fast revision and quick overview of the subject.
Though students in today's world are broadly influenced by technology, they are cautious about the overuse or misuse of it. One study noted that students preferred PPT over the use of TOHP, but that in some instances the content of the PPT presentation distracted students (Bartsch \& Cobern 2003). It is stated that the student becomes a passive observer rather than an active participant in PPT teaching (Casanova \& Casanova 1991), and it reduces the interactive discussion between the teacher and the students (Garg et al., 2004). In a survey in Pakistan, students reported disliking both TOHP and PPT slides due to monotony of the classes and lack of interest it generates among both students and teachers. The tendency to go fast is common because of the ease of delivery of the material (Singh et al., 2009). In one study students opined that a judicious use of animations and sufficient time to take down notes (Seth et al., 2010b).

Combined teaching with blackboards and PPT with animations has been considered the ideal way to teach (Singh et al., 2009). A chalkboard may be more student centred while PPT more teacher-centred (Creed 1998). Use of exciting and innovative animation based learning using PPT and board teaching can be used together to bring about maximum pedagogical benefits to the students (Singh et al., 2009).

In this study, transparencies were considered 'out dated, unclear, unattractive, boring and not useful' by majority of the students, and illustrations and graphics are preferred for better retention. Less than $2 \%$ of students suggested that 'transparencies may be used to 
summarise important points or to break the monotony of power points in all sessions'. This issue has been addressed by a few studies. TOHP expands the potential of blackboard teaching by enabling combinations of text, tables and diagrams (Chaudhary et al., 2009).

Students learn best when they are engaged by material that is presented in variety of ways and formats (Tennyson, 1988). Findings of this study can facilitate appropriate utilisation of teaching learning media for quality learning experience. Faculty should take advantage of this knowledge so as to maintain interest and enthusiasm among the students.

\section{Conclusion}

Though PPT was found suitable for the visual content and presentation style, students preferred a combination of PPT and blackboard for lecture delivery, while use of transparencies was not a preferred method. These findings suggest need for changes in the current practice to facilitate overall improvement of teaching learning experience.

\section{References}

Bartsch, R.A. \& Cobern, K.M. (2003) Effectiveness of PowerPoint presentations in lectures. Computers and Education, 41, pp. 77-86.

Brown, G. \& Atkins M. (1988) Effective Teaching in Higher Education. London, UK: Routledge.

Casanova,J. \& Casanova, S. L. (1991) Computers as electronic blackboard: Remodelling, the organic chemistry lecture, Educational communications Review, pp. 31-34.

Chaudhary, R., Dullo, P. \& Gupta, U. (2009) Attitude of $1^{\text {st }}$ MBBS medical students about two different visual aids in physiology lectures, Pakistan Journal of Physiology, 5, 2, pp. 16-19.
Creed, T. (1998) PowerPoint No! Cyberspace Yes! In: The National Teaching and Learning Forum. New York, NY: Greenwood Publishing Group.

Garg, A., Rataboli, P.V. \& Muchandi, K. (2004) Students' opinion on the prevailing teaching methods in pharmacology and changes recommended, Indian Journal of Pharmacology, 36, pp. 155-8.

Novelli, E.L.B. \& Fernandes, A.A.H. (2007) Students' preferred teaching techniques for biochemistry in biomedicine and medicine courses, Biochemistry and Molecular Biology Education, 35, pp.263-266.

Prasad, S., Roy, B. \& Smith, M. (2000) The art and science of presentation: Electronic presentations, Journal of Postgraduate Medicine, 46, pp.193198.

Savoy, A., Proctor, R.W. \& Salvendy G. (2009) Information retention from PowerPoint and traditional lectures. Computers \& Education, 52, pp. 858-867.

Seth, V., Upadhyaya, P., Ahmad, M. \& Kumar, V. (2010a) An assessment of teachers' preference for lecture delivery methods in medical education. Educational Research and Review, 5, 9, pp. 533537.

Seth, V., Upadhyaya, P., Ahmad, M. \& Moghe, V. (2010b) PowerPoint or chalk and talk: Perceptions of medical students versus dental students in a medical college in India. Advances in Medical Education and Practice, 1, pp.11-16.

Singh, S., Singh, S. \& Gautam, S. (2009) Teaching styles and approaches: Medical student's perceptions of animation-based lectures as a pedagogical innovation, Pakistan Journal of Physiology, 5, 1, pp. 16-19.

Tennyson, R. D. (1988) An instructional strategy planning model to improve learning and cognition, Computers in human behavior, 4, pp. 13-22. 